\title{
Ants biting amphibians: a review and new observations
}

$I_{\text {Institute of Zoology, }}$

Poznań University of

Life Sciences, Wojska

Polskiego 71 C, 60-625

Poznań, Poland

Corresponding author,

Tel.: 48531155860

E-mail:traszka.com@,

gmail.com

\author{
Mikołaj Kaczmarski ${ }^{*}{ }^{*}$, Michał Michlewicz ${ }^{1}$, Piotr Tryjanowski ${ }^{1}$
}

\section{KEYWORDS}

Anura; drift fences; Formicidae; frogs; interaction; toads

(cc)BY-NC-ND $\odot 2019$ Mikołaj Kaczmarski et al.

This is an open access article distributed under the Creative Commons Attribution-NonCommercial-NoDerivs license

\section{INTRODUCTION}

Direct damage caused by invertebrates on amphibians mainly concerns predation accident for all we know. Data on vertebrate predation by invertebrates in the literature is scarce, since it is difficult to observe such behavior in natural conditions (Toledo 2005). However, predation behavior toward vertebrates by invertebrates is not as common as the opposite situation, but it is also nothing extraordinary (McCormick \& Polis 1982; Scholtz \& Ralston 2017; Toledo 2005; Bernard \& Samoląg 2014). The most common invertebrate predators are spiders and insects (e.g., Belostomatidae: Carabidae), and the most common habitats are water bodies (McCormick \& Polis 1982; Toledo 2005). Although there is a noticeable amount of information about such predation in water bodies (McCormick \& Polis 1982; Toledo 2005; Linares et al. 2016), cases in terrestrial ecosystems are scarce and mostly concern ground beetles (Coleoptera: Carabidae) (Wizen \& Gasith 2011a; Wizen \& Gasith 2011b; Bernard \& Samoląg 2014). Some authors suggest that there are major knowledge gaps in this regard for terrestrial systems and incidental predation; such events are observed only opportunistically and described as anecdotal data. In the case of small lizards (arboreal gecko), predation rates by invertebrates are responsible for up to $23 \%$ of predation events during an experiment conducted in the wet season in Australia (Nordberg et al. 2018). Therefore, some invertebrates should be considered, at least seasonally, a significant component of food web dynamics, which requires further research. Against this background, other direct and indirect damage conduct by insects on amphibians was not well described yet in specialist literature in our opinion.

Ants can inflict some damage to amphibians most probably when the latter are trapped in some kind of hole or 
crevice and unable to escape. Consequently, it is difficult to conduct research on this topic in strictly natural conditions, but other man-made holes can act as a good substitute for investigating ant attacks on amphibians. One means of conducting such observations can be through the use of pitfall traps, a commonly used approach in both research and conservation projects (Puky 2006; Schmidt \& Zumbach 2008).

Pitfall traps are one of the most commonly used passive traps in herpetological research (Jenkins et al. 2003; Sutherland 2006; McKnight et al. 2015). This method has many advantages including intensive sampling of animals in terms of time and effort and more standardized samples than in visual searches. For amphibians, the system usually consists of a fence and some empty containers (e.g., buckets), which are buried to be flush with soil level (Sutherland 2006). Amphibians (and other species) fall into pitfalls and become trapped (Willson \& Gibbons, 2009). Use of this method to study vertebrates (in particular amphibians) requires regular and frequent checking in order to reduce the negative impact of prolonged capture (Sutherland 2006). Extending the scope of routinely collected data from pitfall traps during mitigation projects may be an opportunity to describe inter-species interactions occurring inside traps. It is worth mentioning that descriptions of amphibian predation in pitfall traps by mammals (Jenkins et al. 2003; Ferguson 2006; Ferguson et al. 2008), birds, or snakes (Enge 1997; Willson \& Gibbons 2009) have been reported in the literature. Some authors proposed a technical modification to prevent predation (Sutherland 2006) but agile predators (e.g., snakes) can still enter pitfalls and consume animals (Ferguson 2006). On the other hand, information on insect direct damage of amphibians in pitfall traps is scarce; as far as we know only fire ants, Solenopsis invicta Buren, 1972, and some beetles have been thus recorded (Enge 1997; Enge 2001).

However, in this context, there are no solutions to protect amphibians from invertebrate attacks.

Following rare but repeated observations of ant attacks on amphibians in our pitfall trap system, we decided to investigate this phenomenon. We also try to explain the observed frog-ant interactions.

\section{MATERIALS AND METHODS}

All observations were made in a drift fence system on a road intersection in Poznań, Poland. This road crosses a valuable natural area and adjacent forest complex that is an ecological corridor (Dyderski et al. 2014). On both sides of the road temporary fences have been established for seasonal protection of the local amphibian population during migration. The fence is equipped with pitfall traps about every $15 \mathrm{~m}$ on average (totally $800 \mathrm{~m}$ of fence and 50 traps). In 2012-2017, during mitigation work, pitfalls were checked daily in the morning in two periods: (1) spring migration in March-May and (2) autumn dispersion of juveniles in August-October. A total of 6838 amphibians were captured, mostly Anura-6228 individuals (M. Kaczmarski, unpublished data). During hot and dry periods, to avoid desiccation of captured animals, checking was conducted twice a day. In the study area 11 species of amphibians (Kaczmarek et al., 2015) and 15 ant species (M. Michlewicz, unpublished data) occur. Trapped amphibians were carefully checked for ants and, when found, the amphibians were measured (snoutvent length, SVL, with calipers to an accuracy of $0.1 \mathrm{~mm}$ ).

\section{RESULTS}

We recorded 29 cases of ants attacking amphibians by a total of 94 ants (Table 1 ), which represent only $0.47 \%$ of captured animals. Four amphibian taxa, Rana temporaria Linnaeus, 1758, Pelophylax esculentus complex, Bufo bufo Linnaeus, 1758, and Pelobates fuscus Laurenti, 1768, were observed with ants biting their back, cloaca, armpits, or hind legs (Fig. 1 \& 2). No case on ant attacks on Caudata (smooth newt Lissotriton vulgaris Linnaeus, 1758) or on other Anura species occurring in this site was noted. Ants inflicted attack mostly on juvenile Anura of taxa dominant inside pitfall trap, but in the case of $B$. bufo only on adult individuals (Fig. 2C \& D). Most cases (27 out of 29) were recorded in the autumn (Table 1 ).

The number of ants biting on amphibians was positively correlated with amphibian body length $(r=0.407, n=$ 28, $P<0.05)$.

Three ant species were recorded performing this behavior (Table 1). Myrmica rubra Linnaeus, 1758, was recorded biting the $P$. esculentus complex, $P$. fuscus, and $B$. bufo individuals and kept mostly to the hind legs or, rarely, forelegs and armpits. Lasius fuliginosus Latreille, 1798, was observed biting $R$. temporaria and the $P$. esculentus complex in the cloaca area, belly, and legs of the amphibians. Formica polyctena Förster, 1850, was observed biting B. bufo in the hind legs, bottom, and armpits. Detailed information is available in the Supplementary materials (SM)-Appendix 1.

In the case of two $P$. fuscus, individuals bitten by ants were weak, and had movement problems and swollen bodies. After the removal of the ants they returned to a good condition within $48 \mathrm{~h}$ and were released. Dead amphibians both with ants bitten on the body and without any ants, as well as some dead ants, were found in the pitfall traps, but reasons for death are unknown (SM-Appendix 1).

\section{DISCUSSION}

We report cases of ants biting adult frogs and toads, which is a novelty, because so far most researchers have focused only on direct damage by ants on amphibians. We did not notice any case of ant attacks on L. vulgaris, probably because of greater agility (Caudata can easily remove ants using the snout or eat them).

According to our knowledge, four ant species are known to be predators of amphibians. The first of these, Paraponera clavata Fabricius, 1775, is a giant, predatory species from South America, which hunts frogs from the genus Eleutherodactylus Duméril and Bibron, 1841, and strawberry 
Table 1. Summary of all reported cases of ants biting amphibians recorded during our study.

\begin{tabular}{|c|c|c|c|c|c|c|c|c|c|c|c|}
\hline \multirow{2}{*}{ Ant species } & \multirow{2}{*}{$\begin{array}{l}\text { Amphibian } \\
\text { species* }\end{array}$} & \multirow{2}{*}{$\begin{array}{c}\text { Num- } \\
\text { ber } \\
\text { of } \\
\text { cases }\end{array}$} & 2012 & 2013 & 2014 & 2015 & 2016 & \multicolumn{4}{|c|}{ Ant bites of amphibians } \\
\hline & & & \multicolumn{4}{|c|}{ Autumn } & Spring & Min & Max & Mean & Total \\
\hline Myrmica rubra & PEC & 4 & 4 & - & - & - & - & 2 & 9 & 5.0 & 20 \\
\hline & RT & 5 & 1 & - & - & 4 & - & 1 & 2 & 1.6 & 8 \\
\hline & $\mathrm{PF}$ & 2 & - & 1 & 1 & - & - & 3 & 14 & 8.5 & 17 \\
\hline & BB & 1 & - & 1 & - & - & - & 5 & 5 & 5.0 & 5 \\
\hline & & 12 & 5 & 2 & 1 & 4 & - & 1 & 14 & 4.2 & 50 \\
\hline Lasius fuliginosus & PEC & 11 & - & 9 & 2 & - & - & 1 & 7 & 2.2 & 24 \\
\hline & RT & 3 & - & 3 & - & - & - & 2 & 4 & 3.0 & 9 \\
\hline & & 14 & - & 12 & 2 & - & - & 1 & 9 & 2.4 & 33 \\
\hline Formica polyctena & BB & 2 & - & & - & - & 2 & 2 & 4 & 3.0 & 6 \\
\hline Species indefinite & RT & 1 & - & 1 & - & - & - & 5 & 5 & 5 & 5 \\
\hline Total & & 29 & 5 & 15 & 3 & 4 & 2 & 1 & 14 & 3.2 & 94 \\
\hline
\end{tabular}

*PEC-Pelophylax esculentus complex; RT-Rana temporaria; PF-Pelobates fuscus; BB-Bufo bufo

poison frogs Oophaga pumilio Schmidt, 1858 (Fritz et al. 1981). Iridomyrmex purpureus Smith, 1858, an ant from Australia, is known to hunt small individuals of the cane toad Rhinella marina Linnaeus, 1758, after its metamorphosis (Clerke \& Williamson 1992). The red imported fire ant S. invicta hunts Houston toad Anaxyrus houstonensis Sanders, 1953 (Thomas \& Allen 1997; Brown et al. 2012), and the mole salamander Ambystomatal talpoideum Holbrook, 1838 (Todd et al. 2008). Lastly, the red wood ant Formica rufa Linnaeus, 1761, is the only temperate species known to predate amphibians, and is known for hunting juvenile common toads B. bufo (Zuffi 2001).

However, the interaction between ants and amphibians found in pitfall traps is not necessarily direct predation, because:

1) The pitfall traps collect both ants and amphibians but the former can escape from them easily. When more and more ants fall into, or simply aggregate in, the pitfall traps, they react to the sudden movements of the amphibians and start to bite them. Similar results (i.e., toleration but biting after sudden movements) were found in amphibian and ant hiding places in the savanna (Rödel \& Braun, 1999).

2) Ants use pitfall traps to prey on invertebrates; but when an amphibian was caught inside the trap, ants tried to attack it. However, the number of ants was probably too low to kill the amphibian.

3) Amphibians inside pitfall traps might be a little desiccated and generally weaker (Parris 1999), so they are probably an easier target for ants and other predators. In this case, the ants can play the role of scavengers.

Pitfall traps in our study were probably used by ants as a food reservoir rather than a nesting site because there was no evidence of eggs, larvae, pupae, or a nest in the buckets during observations. However, there is a possibility that the ant nest was located under the buckets, as they possess drainage holes in the bottom. No amphibians with ants on them were found outside the pitfall traps. This is probably because of the fact that in the restricted area of pitfall traps it is easier for an ant to bite an amphibian. Every ant that bit the anurans was alive and able to release itself when amphibians were released from the pitfall traps. In Europe, probably only red wood ant (and its relatives from the subgenus Formica sensu stricto) can be actual predators of amphibians, since it is a big, non-selective predatory species, which can forage within about $100 \mathrm{~m}$ from its nest (sometimes further) (Czechowski et al. 2012). This is in agreement with the results found by Zuffi (2001). However, in some cases (e.g., in pitfall traps as documented here), 

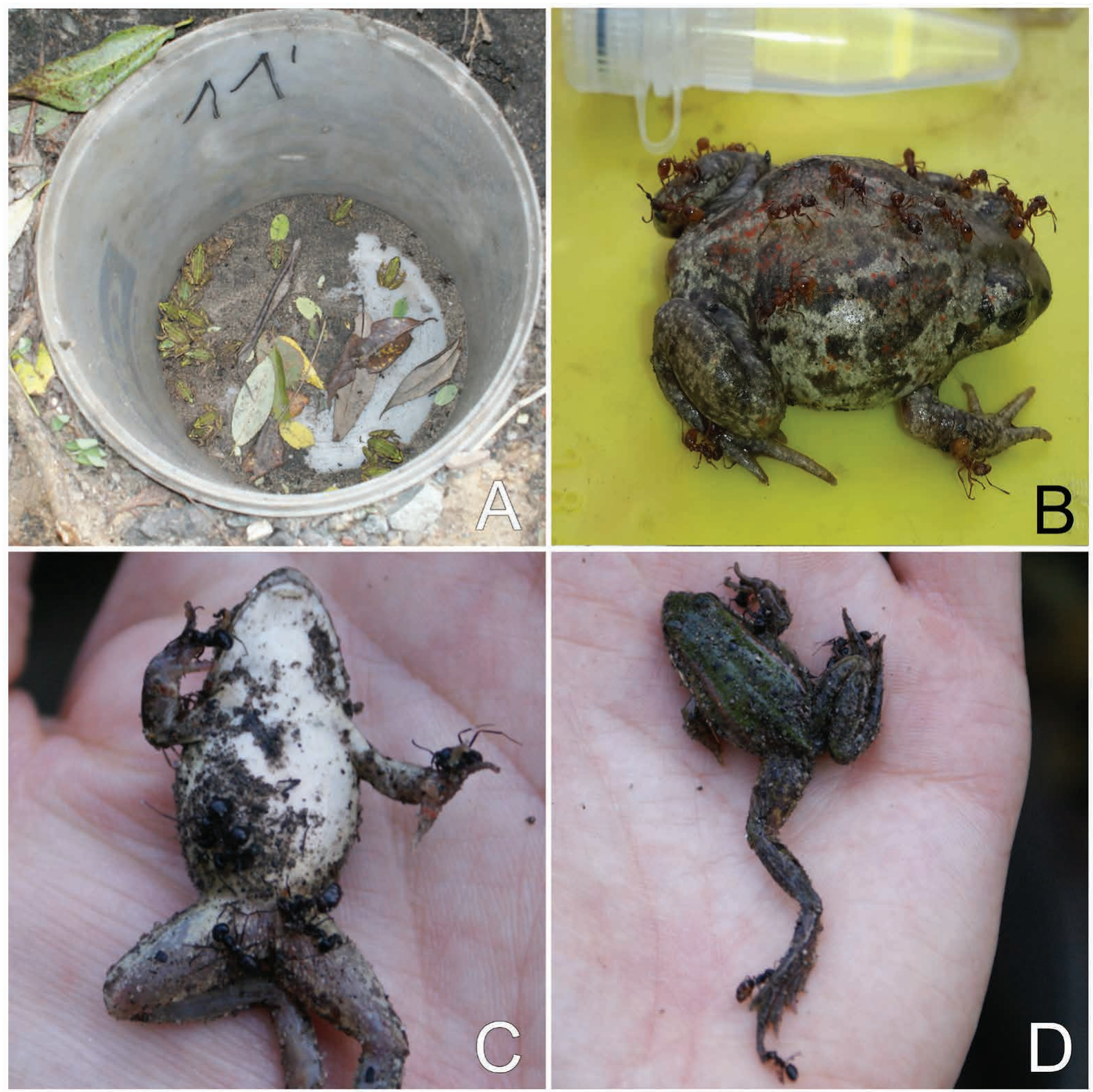

Figure 1. (A) Typical bucket used as a pitfall trap (without platform for insects/mammals). Inside are 18 individuals of the Pelophylax esculentus complex (September 24, 2013). (B) Swollen Pelobates fuscus with Myrmica rubra after removal from the pitfall trap (October 21, 2014). (C), (D) Pelophylax esculentus complex attacked by Lasius fuliginosus in the bucket, the abdominal and dorsal view with ants (October 22, 2013).

other ant species can be a threat to amphibians, even if checks are performed daily.

Due to the low frequency of the phenomenon, we do not have the opportunity to test differences in the occurrence of attacks for individual taxon or year. However, we documented a larger number of ants attacking bigger amphibians, which is in agreement with the results by Ward-Fear et al. (2010). This is probably because bigger individuals provide more sites for biting by ants. Different species of ants can also affect the various behaviors of amphibians and predator avoidance. Long et al. (2015) observed that, in experimental conditions, southern toad Anaxyrus terrestris Bonnaterre, 1802, increased move- ments in the presence of red imported fire ants compared to native pyramid ants Dorymyrmex bureni Trager, 1988.

Despite the fact that pitfall traps are widely used in amphibian conservation (Puky 2006, Schmidt \& Zumbach, 2008), invertebrate biting is not a commonly reported issue. Pitfall traps may be a threat for many non-target groups of animals. Particularly little is known about active hunting of amphibians inside pitfall traps by predatory invertebrates. The phenomenon may have a similar negative effect as does the predation by vertebrates, such as snakes or mammals, in such structures (Ferguson 2006; Ferguson et al. 2008). On the other hand, the fact that this method is commonly used makes the 

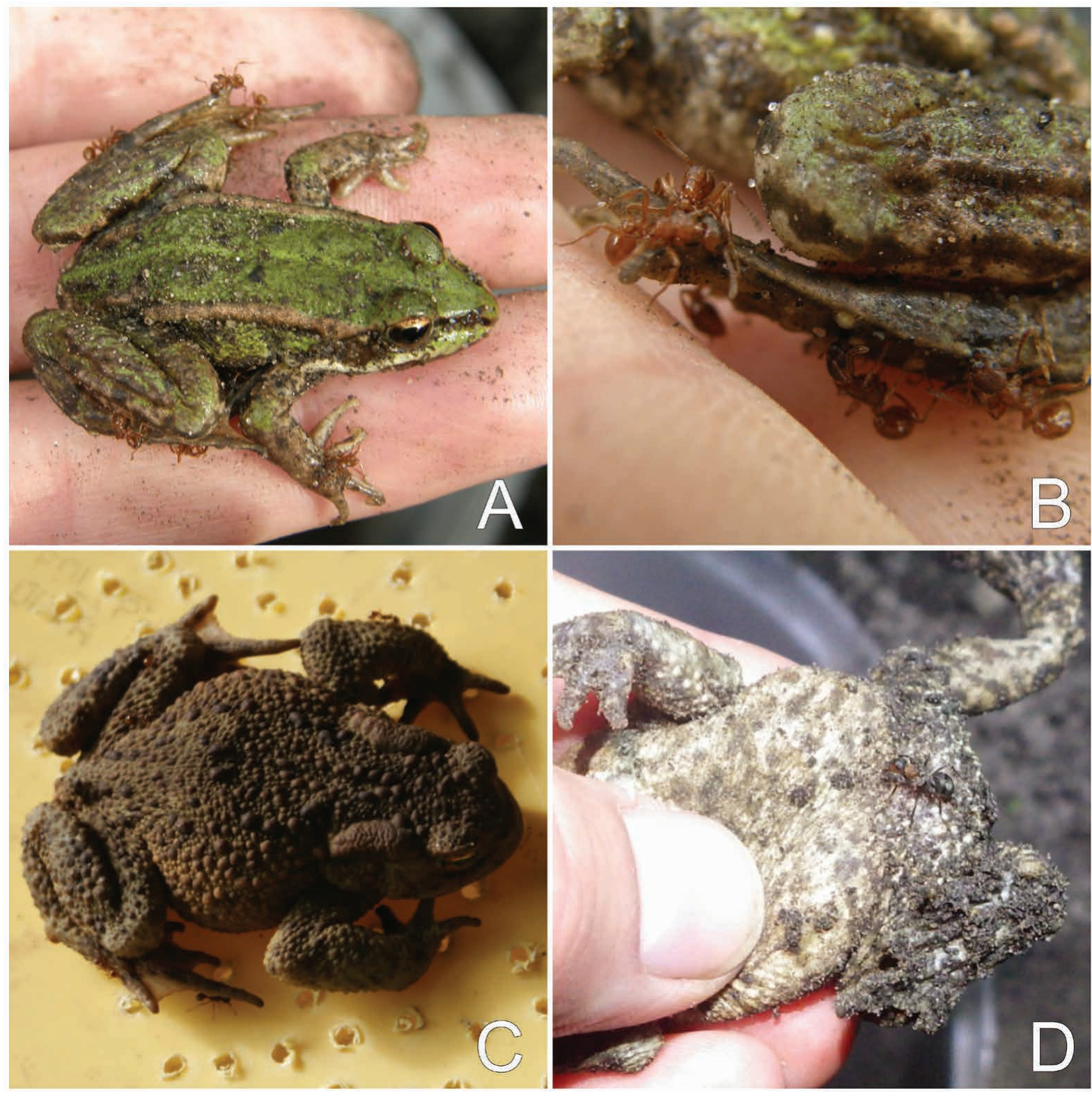

Figure 2. (A) Pelophylax esculentus complex attacked by Myrmica rubra; (B) the same individual-the hind limb with ants (October 5, 2012). (C) Bufo bufo with Myrmica rubra after removal from the pitfall trap (September 24, 2013). (D) Formica polyctena bite on the belly of Bufo bufo (March 31, 2016).

reporting of our results important so that other interactions can be observed.

In contrast to the majority of insects, ants do not show a clear diurnal pattern (Hölldobler \& Wilson 1990) and it is unlikely to prevent the attacks on amphibians by changing the timing of pitfall checks. The only possible way to prevent the negative effect of this interaction is more frequent checks, which would prevent amphibians drying out, and would not expose them to aggressive ants for a long period of time.

\section{Acknowledgments}

We thank Alex Fleasch, Grzegorz Gołębniak, Jan M. Kaczmarek, and Piotr Kazimirski (members of The Naturalists' Club "Klub Przyrodników"-NGO) and Anna M. Kubicka for help in the fieldwork and provision of valuable data. We thank Tim $\mathrm{H}$. Sparks for English editing. Amphibian handling was performed according to the Regional Directorate for Environmental Protection (RDOŚ) permission no. DOP-OZGIZ.6401.02.8.2012. JRO, WPN-II.6401.91.2013.EH, WPN-II.6401.55.2014.AG, WPNII.6401.68.2015.AS.2, and WPN-II.6401.67.2016.AC.2. 
Bernard, R. \& Samoląg, J. (2014) An event of underground predation on a wintering caudate amphibian by a carabid beetle. Entomologica Fennica, 25, 157-160.

Brown, D.J., DeVolld, B., Nowlin, W.H. \& Forstner, M.R. (2012) Fire ants in houston toad habitat: annual activity and responses to canopy cover and fire. Journal of Fish and Wildlife Management, 3, 142-149.

Clerke, C.B. \& Williamson, I. (1992) A note on the predation of Bufo marinus juveniles by the ant Iridomyrmex purpureus. Australian Zoologist, 28, 64-67.

Dyderski, M.K., Gdula, A.K. \& Wrońska-Pilarek, D. (2014) Vascular plants of newly created 'Bogdanka I' and 'Bogdanka II' ecological lands in Poznań. Nauka Przyroda Technologie, 8:\#44. Available at: http://www.npt.up-poznan.net/pub/art_8_44.pdf.

Enge, K.M., (1997) A standardized protocol for drift-fence surveys. Technical Report No. 14 (pp. 1-75). Florida Game and Fresh Water Fish Commission.

Enge, K.M. (2001) The pitfalls of pitfall traps. Journal of Herpetology, 35, 467-478.

Ferguson, A.W. (2006) A device for excluding predators from pitfall traps. Herpetological Review, 37, 316-317.

Ferguson, A.W. Weckerly, F.W., Baccus, J.T. \& Forstner, M.R. (2008) Evaluation of predator attendance at pitfall traps in Texas. The Southwestern Naturalist, 53, 450-457.

Fritz, G., Rand, A.S. \& DePamphilis, C.W. (1981) The aposematically colored frog, Dendrobates pumilio, is distasteful to the large, predatory ant, Paraponera clavit. Biotropica 13, 158-159.

Hölldobler, B. \& Wilson, E.O., 1990. The Ants. Harvard: Harvard University Press. Jenkins, C.L., Mcgarigal, K. \& Gamble, L.R. (2003) Comparative effectiveness of two trapping techniques for surveying the abundance and diversity of reptiles and amphibians along drift fence arrays. Herpetological Review, 34, 39-42.

Kaczmarek, J.M., Kaczmarski, M. \& Pędziwiatr, K. (2015) Atlas of amphibian distribution in Poznan - a tool for efective conservation. In: Nowak, M., (Ed.), Scientific, Technological and Legal Background of Creating Integrated Biotic Databases (pp. 67-74). Poznan: Adam Mickiewicz University Press.

Linares, A.M. Horta Maciel-Junior, J.A., Santo De Mello, H.E. \& Fortes Leite, F.S. (2016) First report on predation of adult anurans by Odonata larvae. Salamandra, 52, 42-44.

Long, A.K. Knapp, D.D., Mccullough, L., Smith, L.L., Conner, L.M. \& Mccleery, R.A. (2015) Southern toads alter their behavior in response to red-imported fire ants. Biological Invasions, 17, 2179-2186.

McCormick, P. \& Polis, G.A. (1982) Arthropods that prey on vertebrates. Biological reviews, 57, 29-58.
McKnight, D.T. Harmon, J.R., McKnight, J.L. \& Ligon, D.B. (2015) Taxonomic biases of seven methods used to survey a diverse herpetofaunal community. Herpetological Conservation and Biology, 10, 666-678.

Nordberg, E.J., Edwards, L. \& Schwarzkopf, L. (2018) Terrestrial invertebrates: An underestimated predator guild for small vertebrate groups. Food Webs, 15, e00080.

Parris, K.M. (1999) Review: Amphibian surveys in forests and woodlands. Contemporary Herpetology, 1999, 1-14.

Puky, M. (2006) Amphibian road kills: a global perspective. In: Irwin C., Garrett P. \& McDermott, K., (Eds.), Proceedings of the 2005 International Conference on Ecology and Transportation (pp. 325-338). Raleigh: North Carolina State University.

Rödel, M.-O. \& Braun, U. (1999) Associations between Anurans and ants in a West African savanna (Anura: Microhylidae, Hyperoliidae, and Hymenoptera: Formicidae). Biotropica, 31, 178-183.

Schmidt, B.R. \& Zumbach, S. (2008) Amphibian road mortality and how to prevent it: a review. Herpetological conservation 3, 157-167.

Scholtz, C.H. \& Ralston, C.D. (2017) A beetle (Carabidae: Chlaenius (Epomis) spp.) that eats frogs. African Entomology, 25, 540-543. Sutherland, W.J., 2006. Ecological census techniques: A handbook. Cambridge University Press.

Thomas, L.A. \& Allen, J. (1997): Bufo houstonensis (Houston Toad). Behavior. Herpetological Review, 28, 40-41.

Todd, B.D., Rothermel, B.B., Reed, R.N., Luhring, T.M., Schlatter, K., Trenkamp, L. \& Gibbons, J.W. (2008) Habitat alteration increases invasive fire ant abundance to the detriment of amphibians and reptiles. Biological Invasions 10, 539-546.

Toledo, L.F. (2005) Predation of juvenile and adult Anurans by invertebrates: current knowledge and perspectives. Herpetological Review, 36, 395-400.

Ward-Fear, G., Brown, G.P. \& Shine, R. (2010) Factors affecting the vulnerability of cane toads (Bufo marinus) to predation by ants. Biological Journal of the Linnean Society 99, 738-751.

Willson, J.D. \& Gibbons, J.W. (2009): Drift fences, coverboards, and other traps. In: Kenneth Dodd, C. (Ed.), Amphibian Ecology and Conservation: A Handbook of Techniques (pp. 231-245). New York: Oxford University Press.

Wizen, G. \& Gasith, A. (2011a) An unprecedented role reversal: ground beetle larvae (Coleoptera: Carabidae) lure amphibians and prey upon them. PLoS ONE, 6, e25161.

Wizen, G. \& Gasith, A. (2011b) Predation of amphibians by carabid beetles of the genus Epomis found in the central coastal plain of Israel. ZooKeys, 100, 181-191.

Zuffi, M.A.L. (2001) Bufo bufo (European Common Toad). Red ant predation. Herpetological Review, 32, 100-101. 


\section{APPENDIX 1}

\begin{tabular}{|c|c|c|c|c|c|c|c|c|c|c|c|c|c|c|}
\hline 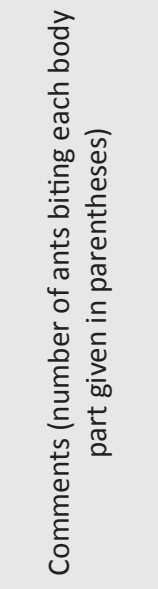 & 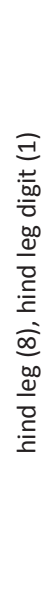 & 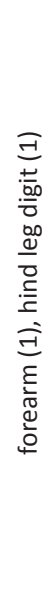 & 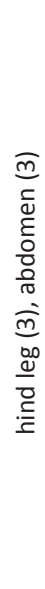 & 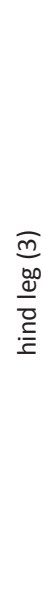 & 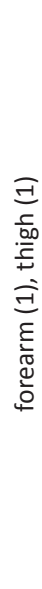 & $\begin{array}{l}\frac{\pi}{\pi} \\
\frac{\pi}{0} \\
\stackrel{0}{\complement}\end{array}$ & $\begin{array}{l}\frac{\pi}{0} \\
\frac{\pi}{0} \\
0 \\
0\end{array}$ & $\begin{array}{l}\frac{\pi}{0} \\
\frac{\pi}{0} \\
\circ \\
\therefore\end{array}$ & 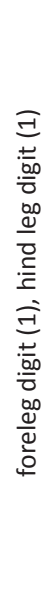 & 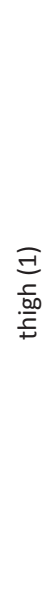 & 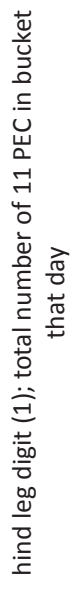 & 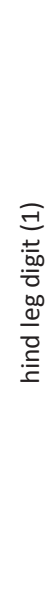 & 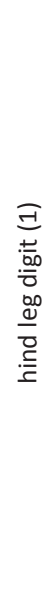 & 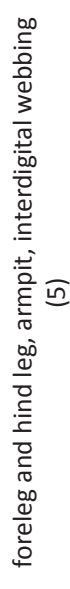 \\
\hline 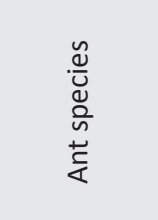 & 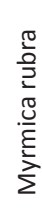 & 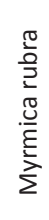 & 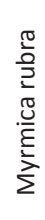 & 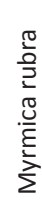 & 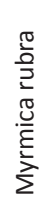 & $\begin{array}{l}\frac{\pi}{\pi} \\
\frac{\pi}{0} \\
\stackrel{0}{\complement}\end{array}$ & 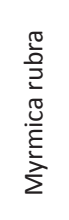 & 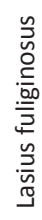 & 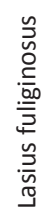 & 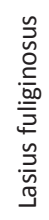 & 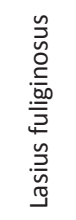 & 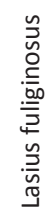 & 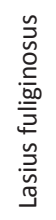 & 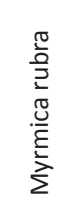 \\
\hline 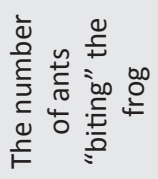 & $a$ & $\sim$ & 0 & $m$ & $\sim$ & in & $m$ & $\sim$ & $\sim$ & $\neg$ & $\rightarrow$ & $r$ & $r$ & in \\
\hline 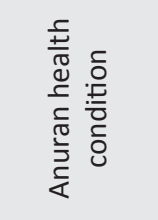 & $\stackrel{\Perp}{\geqq}$ & $\stackrel{\Perp}{\stackrel{\Xi}{ \pm}}$ & $\stackrel{D}{\stackrel{D}{\perp}}$ & $\stackrel{\Perp}{\underline{z}}$ & $\stackrel{\Perp}{\geqq}$ & 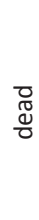 & 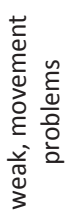 & $\begin{array}{l}\bar{\sigma} \\
\bar{d} \\
0\end{array}$ & $\stackrel{\Perp}{\geqq}$ & $\stackrel{\Perp}{\geq}$ & $\stackrel{\text { I }}{\stackrel{2}{2}}$ & $\stackrel{\infty}{\geqq}$ & $\stackrel{0}{\geqq}$ & $\stackrel{\Perp}{\stackrel{\Perp}{=}}$ \\
\hline 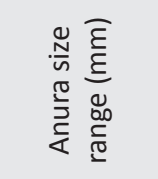 & 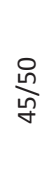 & $\frac{O}{\stackrel{9}{m}}$ & 高 & 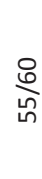 & 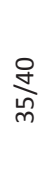 & $\frac{\stackrel{\varphi}{g}}{\partial}$ & $\frac{\text { g }}{\stackrel{m}{m}}$ & 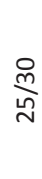 & 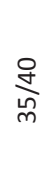 & 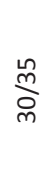 & 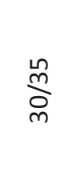 & 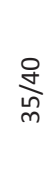 & 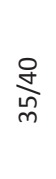 & $\frac{}{\stackrel{ }{\leftrightarrow}}$ \\
\hline $\begin{array}{l}\frac{\tilde{u}}{\tilde{u}} \\
\stackrel{\tilde{\nu}}{n}\end{array}$ & 㟒 & $\stackrel{t}{x}$ & 㟒 & 㟧 & 品 & to & 㟔 & 品 & ta & 㟒 & 㟧 & 㟒 & 㟒 & $\cong$ \\
\hline 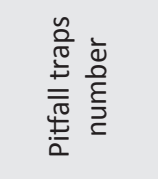 & $\infty$ & $\sigma$ & $\infty$ & $\infty$ & $\sigma$ & $\infty$ & $\sigma$ & $\infty$ & $\ddot{7}$ & $\ddot{~}$ & $\dot{7}$ & $\ddot{7}$ & $\dot{\vec{H}}$ & $a$ \\
\hline 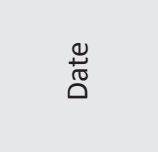 & 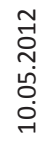 & 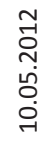 & $\begin{array}{l}\text { Iี } \\
\text { ஸे } \\
0 \\
0 \\
0\end{array}$ & 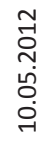 & 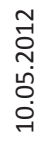 & 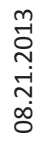 & $\begin{array}{l}m \\
\stackrel{N}{0} \\
\underset{N}{n} \\
\infty \\
0\end{array}$ & $\begin{array}{l}m \\
0 \\
0 \\
\infty \\
\cdots \\
ت \\
0\end{array}$ & 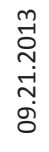 & 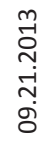 & 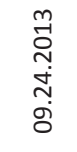 & $\begin{array}{l}m \\
\stackrel{n}{0} \\
\stackrel{+}{0} \\
\stackrel{0}{0}\end{array}$ & $\begin{array}{l}m \\
\stackrel{n}{0} \\
\stackrel{+}{+} \\
\text { ò }\end{array}$ & 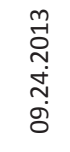 \\
\hline & $r$ & $N$ & $m$ & $\sigma$ & in & 6 & $r$ & $\infty$ & $\sigma$ & 우 & $\exists$ & $\approx$ & $\stackrel{m}{\rightarrow}$ & $\underset{\sim}{\sim}$ \\
\hline
\end{tabular}




\begin{tabular}{|c|c|c|c|c|c|c|c|c|c|c|c|c|c|c|c|}
\hline 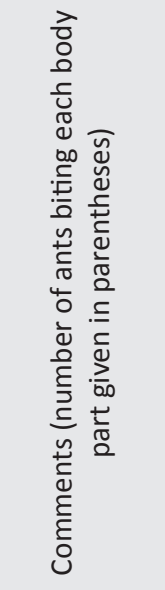 & $\begin{array}{l}\text { I0 } \\
\frac{\pi}{0} \\
\circ \\
0\end{array}$ & 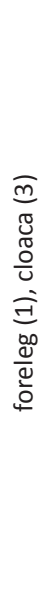 & 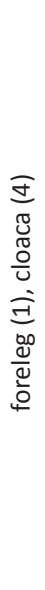 & 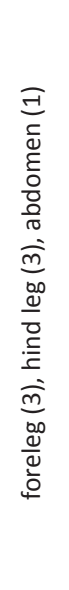 & $\begin{array}{l}\frac{\pi}{0} \\
\frac{\pi}{0} \\
\circ \\
\stackrel{0}{0}\end{array}$ & 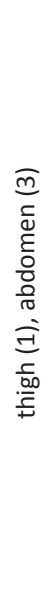 & 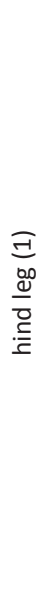 & 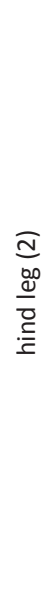 & 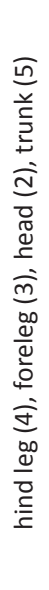 & $\begin{array}{l}\frac{\pi}{0} \\
\frac{\pi}{0} \\
0 \\
0\end{array}$ & 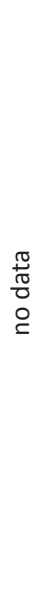 & $\begin{array}{l}\text { 焉 } \\
\text { ○ } \\
\text { @ }\end{array}$ & 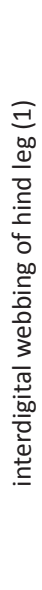 & 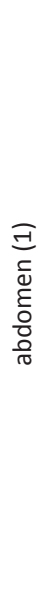 & 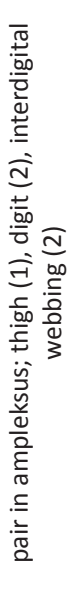 \\
\hline 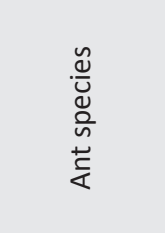 & 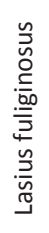 & 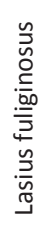 & 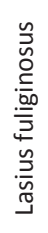 & 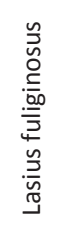 & 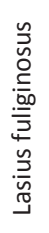 & 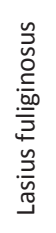 & 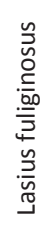 & 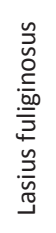 & 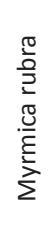 & 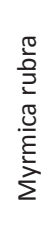 & $\begin{array}{l}\frac{0}{0} \\
\frac{0}{2} \\
\frac{0}{2} \\
\frac{0}{\varepsilon} \\
\frac{2}{2}\end{array}$ & 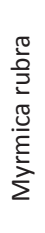 & 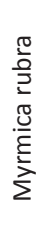 & 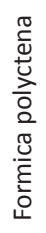 & 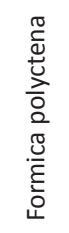 \\
\hline 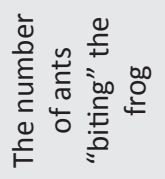 & $r$ & $m$ & $\sigma$ & $r$ & $m$ & 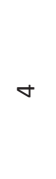 & $r$ & $\sim$ & $\underset{\sim}{\nabla}$ & $r$ & $\sim$ & $N$ & $\dashv$ & $\neg$ & in \\
\hline 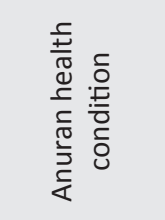 & 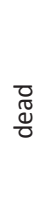 & $\stackrel{0}{\stackrel{0}{=}}$ & 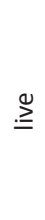 & 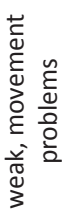 & $\stackrel{\Perp}{\geqq}$ & $\begin{array}{l}\overline{\mathbb{J}} \\
\mathbb{\mathbb { J }}\end{array}$ & $\stackrel{0}{\stackrel{0}{I}}$ & $\stackrel{\nu}{\underline{\Xi}}$ & $\stackrel{0}{\stackrel{0}{I}}$ & $\stackrel{0}{\stackrel{0}{I}}$ & $\stackrel{\Omega}{\geq}$ & $\stackrel{\Perp}{\underline{D}}$ & 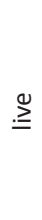 & $\stackrel{0}{\geq}$ & $\stackrel{0}{\stackrel{D}{Z}}$ \\
\hline 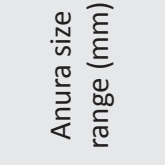 & 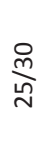 & $\frac{\text { gq }}{g}$ & $\frac{\text { \& }}{\stackrel{g}{g}}$ & 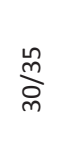 & 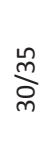 & 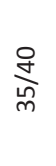 & $\underset{\substack{g \\
m}}{\stackrel{g}{n}}$ & 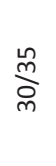 & 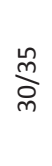 & 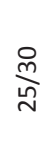 & $\stackrel{\stackrel{N}{\sim}}{\stackrel{N}{N}}$ & $\stackrel{\stackrel{N}{\sim}}{\stackrel{N}{N}}$ & $\stackrel{\sim}{\stackrel{N}{\delta}}$ & $\frac{8}{\stackrel{\circ}{น n}}$ & 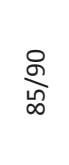 \\
\hline $\begin{array}{l}\frac{\tilde{u}}{\tilde{\Xi}} \\
\stackrel{\tilde{\nu}}{n}\end{array}$ & 总 & uㅗㅁ & 㟒 & 㟧 & $\stackrel{b}{\propto}$ & $\stackrel{b}{x}$ & 㟔 & 㟔 & 늠 & $\stackrel{b}{\alpha}$ & $\stackrel{b}{\alpha}$ & $\stackrel{b}{x}$ & $\stackrel{b}{a x}$ & $\stackrel{\varrho}{\varrho}$ & $\stackrel{\infty}{\infty}$ \\
\hline 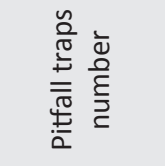 & $\dot{7}$ & $\dot{7}$ & $\dot{7}$ & $\ddot{\exists}$ & $\ddot{z}$ & $\ddot{z}$ & $\dot{\exists}$ & $\ddot{z}$ & $\sigma$ & $\sigma$ & $\sigma$ & $\sigma$ & $\sigma$ & $x$ & $\times$ \\
\hline \multirow[t]{2}{*}{ 苋 } & $\begin{array}{l}m \\
\stackrel{n}{0} \\
N \\
\dot{0} \\
0 \\
\dot{\sigma}\end{array}$ & 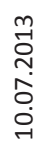 & 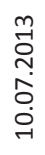 & 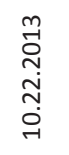 & $\begin{array}{l}m \\
\stackrel{N}{0} \\
\stackrel{n}{n} \\
\stackrel{-}{0}\end{array}$ & 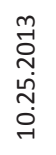 & 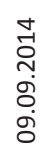 & 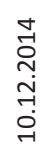 & 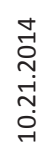 & 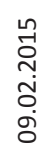 & 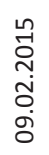 & 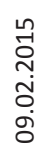 & 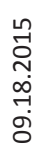 & 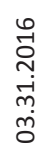 & 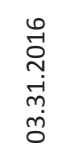 \\
\hline & 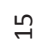 & $\stackrel{\bullet}{\sim}$ & न & $\stackrel{\infty}{\sim}$ & 구 & $\stackrel{\sim}{\sim}$ & $\vec{N}$ & $\approx$ & $\stackrel{\varpi}{\sim}$ & $\stackrel{\sim}{\sim}$ & $\stackrel{\sim}{\sim}$ & $\stackrel{\sim}{\sim}$ & $\grave{\lambda}$ & $\stackrel{\infty}{\sim}$ & নి \\
\hline
\end{tabular}

